\title{
Mechanical behavior and durability of latex modified mortars
}

\author{
Benali $\mathrm{Y}^{*}$, Ghomari F
}

EOLE Laboratory, Faculty of Technology, University Abou Bekr Belkaid, Tlemcen, Algeria.

* Corresponding Author: benaliyacine_gc@yahoo.fr

Received: 10-02-2018

Revised: 15-05-2018

Accepted: 19-05-2018

\begin{abstract}
This article summarizes the results of an experimental program developed on latex-modified mortars. Fluidity tests, compressive strength tests, flexural strength tests, water absorption tests, adhesion tests on clay bricks and cementitious substrates were carried out. The test bodies were prepared by the pre-wetting method with different latex contents while partially substituting Portland cement by two types of latex: StyreneButadiene (SBR) and Styrene Acrylic (SA). In addition, samples of ordinary mortars are made in parallel as references.

The experimental results showed that the substitution of cement in mortars produced a notable improvement on fluidity and adhesion. In the case of clay substrates, a cohesive failure in the support above $10 \%$ substitution has been reported; whereas the rupture is always at the interface for all the mixtures tested on cementitious substrates. An improvement was also noted on the flexural tensile strength beyond 60 days. On the other hand, the compressive strength of the polymer mortars decreased with the substitution rate of cement for all the maturities studied. As for the absorption of water, the results show a clear reduction in the percentage of water absorption by increasing the substitution rate.
\end{abstract}

Key words: Latex modified mortars, fluidity, absorption, strength, adhesion.

\section{Introduction}

Synthetic polymeric additives such as latexes, redispersible polymer powders, water-soluble polymers, and liquid resins have been introduced into cement mortar to obtain the polymermodified mortars. The use of these materials for repair work, restoration, facade coatings, tile adhesives, sealing coatings, decorative coating and external thermal insulation are increasing more and more since the $1960 \mathrm{~s}$ (Said, 2016).

The latex polymers, which are usually manufactured by emulsion polymerization technique (very successful process from the technical and environmental point of view, because water is used as a solvent and also the amount of volatile organic compounds (VOCs) released during their preparation and application is negligible, etc.) Erdmenger et al. (2010), Amaral (2004), Thickett and Gilbert (2007), prove to be the most commonly used polymers (Benali and Ghomari, 2017; Diab, 2014; Xu, 2016). They are marketed as very small (0.05-5 pm in diameter) polymer particles dispersed in water, often milky white (Al-Zahrani, 2003).

The literature shows that there is a variety of types of latex, depending on the kind of monomers or polymers used to manufacture them. The choice of a type of latex depends on the specific properties required for the application (Benali and Ghomari, 2017; Balayssac, 2011). Styrenebutadiene rubber (SBR) and styrene-acrylic (SA) are most widely used latex (Eren, 2017; Benali and Ghomari, 2017).

From the beginning, the mix proportions of modified systems has always been based on a simple combination of cement, water, sand and latex, associated with a polymer/cement ratio, generally ranging from 5 to $20 \%$ of dry latex extracts, depending on the weight of cement in the mixture. 
(Benali and Ghomari, 2017; ACI Committee 548, 2003). The various formulations are used not only to improve the properties of conventional mortars by the formation of latex network and membranes, but also as an admixture to reduce the water content into the mixture (Al-Zahrani, 2003; Diab, 2013), due to the presence of high range super plasticizer agent on latex constituents (Diab, 2013).

During the curing time, the evaporation of the mixing water from the cement paste-latex emulsion system along with the cement hydration leads to film and co-matrice formation (Benali and Ghomari, 2017; Eren, 2017). These two elements fill the open and capillary pores of the matrix, thus improving the cohesion between the aggregates and the cement paste at the interface, and increasing the compactness of the hardened material. This will therefore ameliorate its flexural and tensile strengths, its adhesion to different substrates as well as its durability, while slowing down its permeability to water and also the diffusion of aggressive species, such as carbon dioxide, chlorides, and sulfates. Moreover, latex-modified cementitious materials have better water retention, sufficient entrainment of air, and also a better fluidity (Benali and Ghomari, 2017; Parghi and Alam, 2016; Diab, 2013; Ramli and Tabassi, 2012b).

This investigation aims to study the effect of using two types of synthetic latex: styrene butadiene (SBR) and styrene acrylic (SA), as materials replacing Portland cement at the proportions of $0,2.5,5,10,15$ and $20 \%$ (by weight). The main objective is to highlight the influence of these materials on the mechanical properties, adhesion, and durability of conventional mortars, though the properties of cement mortars can be improved by the addition of latex as a water reducer plasticizer. The modification mechanism, through the replacement of Portland cement by latex (because its production is energy-hungry and it is responsible for several environmental damages), is not clear yet; and a lot of research work needs to be performed. Our hope is to use them for repair works and to manufacture protective mortars and coatings as well.

\section{Experimental program}

\subsection{Materials used}

A Portland cement compound of type CPJ CEM II / A 42.5, meeting the Algerian standard NA 44, from the cement plant of Beni-Saf, in the Wilaya of Ain Temouchent, was used. Its main constituents are clinker, natural pozzolan of volcanic origin from the deposit of Bouhamidi (Beni-Saf, Algeria), and gypsum. The chemical composition of this cement is given in Table 1, and its physical characteristics are summarized in Table 2.

Table 1. Chemical composition of cement.

\begin{tabular}{|c|c|}
\hline Compounds & $(\%)$ \\
\hline \hline $\mathrm{SiO}_{2}$ & 22.17 \\
\hline $\mathrm{Al}_{2} \mathrm{O}_{3}$ & 6.18 \\
\hline $\mathrm{Fe}_{2} \mathrm{O}_{3}$ & 3.62 \\
\hline $\mathrm{CaO}$ & 59.45 \\
\hline $\mathrm{MgO}$ & 1.05 \\
\hline $\mathrm{SO}_{3}$ & 2.63 \\
\hline $\mathrm{K}_{2} \mathrm{O}$ & 0.49 \\
\hline $\mathrm{Na}_{2} \mathrm{O}$ & 0.19 \\
\hline $\mathrm{Cl}$ & 0.004 \\
\hline $\mathrm{P}_{2} \mathrm{O}_{5}$ & 0.18 \\
\hline $\mathrm{TiO}_{2}$ & 0.43 \\
\hline $\mathrm{Loi}$ & 2.62 \\
\hline
\end{tabular}


Table 2. Physical characteristics of cement.

\begin{tabular}{|l|c|}
\hline \multicolumn{1}{|c|}{ Test } & Result \\
\hline \hline Bulk density $\left(\mathrm{T} / \mathrm{m}^{3}\right)$ & 1.01 \\
\hline Specific gravity (Densitometer Le Chatelier) $\left(\mathrm{T} / \mathrm{m}^{3}\right)$ & 3.02 \\
\hline Blaine's specific area $\left(\mathrm{cm}^{2} / \mathrm{g}\right)$ & 3597 \\
\hline
\end{tabular}

The sand used is crushed limestone sand $0 / 3 \mathrm{~mm}$, from the quarry of Djebel Abiod of (ENG ), Sidi Abdelli, in Tlemcen (Algeria). This choice was made because it is the main quarry that supplies the entire region. The characteristics of this sand are summarized in Table 3 and Fig 1.

The quarry of Jebel Abiod produces clean sand $0 / 4 \mathrm{~mm}$. This sand was passed through a 3.15 $\mathrm{mm}$ mesh sieve. The choice of sieving is dictated by the fact that sand $0 / 3$ is the most frequently type used in the literature for the preparation of mortars. No washing or size correction has been performed for the formulation of various mortars.

Table 3. Identification of physical properties of sand.

\begin{tabular}{|c|c|}
\hline Test & Result \\
\hline \hline Bulk density $\left(\mathrm{T} / \mathrm{m}^{3}\right)$ & 1.43 \\
\hline $\begin{array}{c}\text { Absolute density } \\
\left(\mathrm{T} / \mathrm{m}^{3}\right)\end{array}$ & 2.50 \\
\hline Sand equivalent $(\%)$ & 84.5 \\
\hline $\begin{array}{c}\text { Percentage of fines } \\
(\%)\end{array}$ & 15.7 \\
\hline Fineness Modulus & 3.01 \\
\hline
\end{tabular}

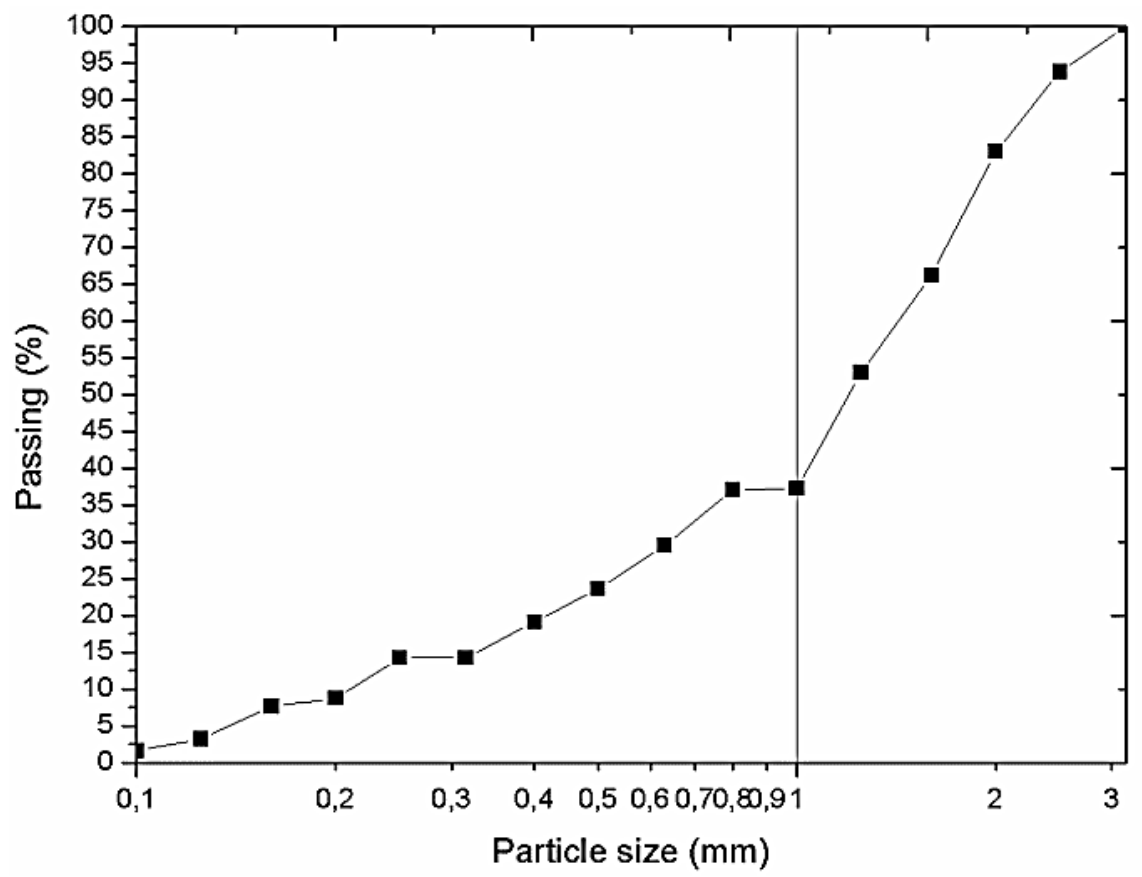

Fig 1. Granulometry of sand used.

Clay bricks, with horizontal perforations and grooves in the coating, of dimensions $(100 \times 200 \times$ $300 \mathrm{~mm}^{3}$ ), were used as substrates for the adhesion tests (see Fig. 2.). These substrates have a bulk density equal to $\left(1.41 \mathrm{~T} / \mathrm{m}^{3}\right)$, and water absorption equal to (13.55\%). This test was performed according to the standard ASTM C373-88 (2006).

Concrete substrates of dimensions $\left(300 \times 300 \times 100 \mathrm{~mm}^{3}\right)$, with grooved in surfaces were made (Fig. 3.) in order to see the influence of a different substrate that the brick on the adhesion by pull off. These concrete have the same composition as the reference concrete that we use in the 
research team "Granular materials" of the laboratory EOLE (Boukli, 2009). It is characterized by $\mathrm{W} / \mathrm{C}$ ratio of 0.5 , a bulk density equal to $2471 \mathrm{~kg} / \mathrm{m}^{3}$, slump (Abrams cone) equal to $6 \mathrm{~cm}$, and water absorption of $6.3 \%$.

Two latex polymers, i.e. styrene-butadiene (SBR) and styrene acrylic (SA) manufactured respectively by SIKA EI DJAZAIRE and TECHNALab, were used. Their physical characteristics are reported in Table 4.

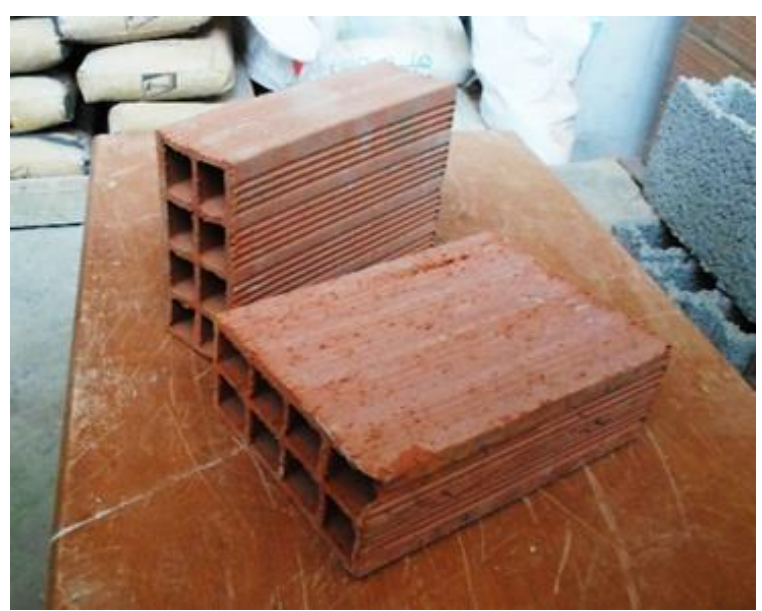

Fig 2. Clay bricks used.

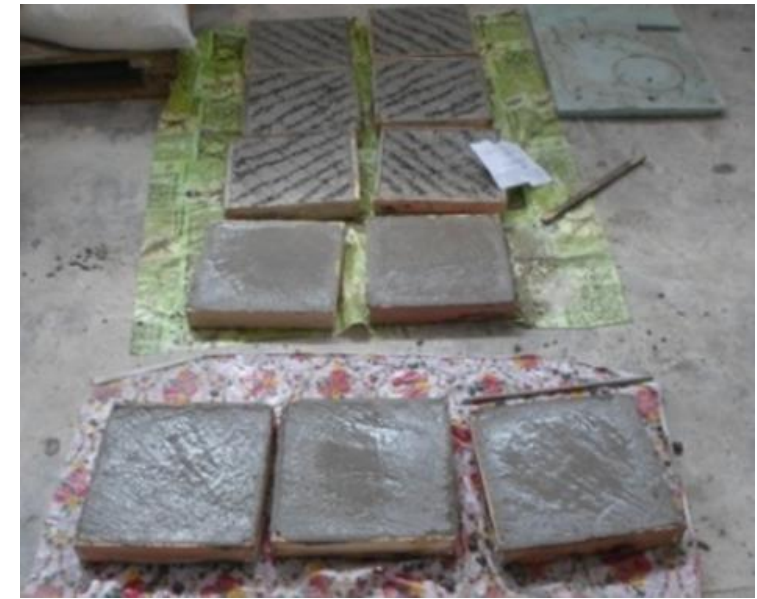

Fig 3. Concrete substrate used.

Table 4. Physical characteristics of latex used.

\begin{tabular}{|c|c|c|c|c|}
\hline \multicolumn{3}{|c|}{ Name of product } & SikaLatex & D-70 \\
\hline \multicolumn{3}{|l|}{ Nature } & $\begin{array}{l}\text { Styrene-Butadiene Rubber } \\
\text { (SBR) }\end{array}$ & $\begin{array}{l}\text { Styrene-Acrylics } \\
\text { (SA) }\end{array}$ \\
\hline \multicolumn{3}{|c|}{ Color and form } & Viscous milky white & Viscous milky white \\
\hline \multicolumn{3}{|c|}{ Odour } & Low & Low \\
\hline \multicolumn{3}{|c|}{ Properties of the film } & Not clear, flexible & Clear, hard \\
\hline \multirow[t]{2}{*}{$\begin{array}{l}\text { Density } \\
\left(\mathrm{T} / \mathrm{m}^{3}\right)\end{array}$} & \multicolumn{2}{|c|}{$\begin{array}{l}\text { According to the manufacturer at } \\
\left(20^{\circ} \mathrm{C}\right)\end{array}$} & 1.02 & - \\
\hline & \multicolumn{2}{|r|}{$\begin{array}{l}\text { Measured in the laboratory at } \\
\left(19^{\circ} \mathrm{C}\right)\end{array}$} & 1.01 & 1.07 \\
\hline \multicolumn{3}{|c|}{$\begin{array}{l}\text { Viscosity }\left(\mathrm{cps}, 30^{\circ} \mathrm{C}\right) \\
\text { (Brookfield RVT } 20 \mathrm{rpm})\end{array}$} & - & $1.5-1.6$ \\
\hline \multirow{2}{*}{\multicolumn{2}{|c|}{$\begin{array}{l}\text { total bulk solids } \\
(\%)\end{array}$}} & According to the manufacturer & 50 & $(50 \pm 1)$ \\
\hline & & Measured in the laboratory & 45 & 50 \\
\hline \multirow{2}{*}{\multicolumn{2}{|c|}{$\mathrm{pH}$}} & According to the manufacturer & 7.5 & - \\
\hline & & $\begin{array}{l}\text { Measured in the laboratory at } \\
\left(19^{\circ} \mathrm{C}\right)\end{array}$ & 9.65 & 7.90 \\
\hline \multicolumn{3}{|c|}{ Particle size $(\mu \mathrm{m})$} & - & $0.1-0.3$ \\
\hline \multicolumn{3}{|c|}{ Minimum temperature of film forming (MFFT), ${ }^{\circ} \mathrm{C}$} & - & 17 \\
\hline \multicolumn{3}{|c|}{ Glass transition temperature $(\mathrm{Tg}),{ }^{\circ} \mathrm{C}$} & - & +16 \\
\hline \multicolumn{3}{|c|}{ Type of surfactant } & - & nonionic \\
\hline
\end{tabular}

\subsection{Method of preparation of samples and tests performed}

\subsubsection{Mixes and cures}

Our experimental program consisted in replacing amounts of cement by latex proportions ranging from 2.5 to $20 \%$ of dry extract. The results obtained were compared with reference mortars with similar composition, where cement is the only binder. 
The cement to sand ratio $(\mathrm{C} / \mathrm{S})$ used was $1 / 3$. This choice was prescribed by the fact that these are the most frequent compositions encountered in the literature. The (W/C) ratio used for the manufacture of control mortars was $1 / 2$. This ratio was validated after the mechanical strength test of two mortars with two different ratios (W/C) equal to 0.5 and 0.55 .

The results of the mechanical behavior, at 60 days, are summarized in Table 5 . The values shown are the average of three flexural tensile tests on specimens of dimensions (40x40x160 mm3), and also the average of 6 compression tests performed on fragments recovered from the flexural tensile test. The test samples were immersed in water at $(20 \pm 3){ }^{\circ} \mathrm{C}$, after unmolding at 24 hours, until the age of 60 days. The mixture of the reference mortar components was done according to standard BS EN 196-1 (2005).

From the analysis of the results in Table 5, a slight difference was noted between the mechanical performances of the two formulations, mainly in the compressive strength.

The polymer-modified mortars were prepared with partial substitution of cement at different weight ratios, i.e. $2.5,5,10,15$ and $20 \%$. The substitution ratios were calculated using the total solid content in the latex (see Table 6). As for the (W/C) ratio, two ways to manufacture a latexmodified mortar were found in the related literature (Balayssac, 2011; Barluenga and Hernandez-Olivares, 2004).

- The first is to maintain the $(\mathrm{W} / \mathrm{C})$ ratio constant in order to have a hydration level close to that of the cement paste (typical laboratory procedure).

- The second one, more common (the mortar strength increases), is to adjust the workability of the modified mixture to that of ordinary mortar, usually by adjusting the $(\mathrm{W} / \mathrm{C})$ ratio.

The second method was used in the present study. The fluidity of the SBR-modified mortars was adjusted so as to have a fluidity between 125 and $165 \mathrm{~mm}$ (fluidity of usual mortars, see Table 6), whereas the (W/C) ratio was adjusted so as to have the fluidity of the SA-modified mortar similar to that of the reference mortar $(125 \pm 5) \mathrm{mm}$. This was done using the flow table test, according to the standard ASTM C 1437-07 (2007), while using a frustoconical mold, where the spreading is the average of two perpendicular diameters.

The components of these polymer-modified mortars were mixed according to the pre-wet method. Regarding the literature, the speed, time and procedure of mixing the latex-modified mortars must be carefully chosen in order to prevent the needless air from being trapped. The entrained airs that form when cement and aggregates are mixed with an aqueous polymer solution are not easily removed as they tend to be stabilized by polymers (Kim and Robertson, 1997). As a result, the properties of the mix in the hardened state will deteriorate (Ohama, 1995). To reduce these unnecessary amounts of air, some researchers (Kim and Robertson, 1997; Barluenga and Hernandez-Olivares, 2004) proposed an alternative approach, which is to pre-wet cement and sand with water, then add the latex last (the pre-wetting method).

In order to determine the mechanical parameters and the porosity accessible to water, the molds containing the polymer mortar samples were covered with plastic film, and stored in the laboratory environment. The samples were unmolded after 24 hours, and kept in water for 6 days at $(20 \pm 3){ }^{\circ} \mathrm{C}$ and then in the open air at $(20 \pm 3){ }^{\circ} \mathrm{C}$ with a relative humidity (RH) equal to $55 \pm 10 \%$, until the test at $7,14,28,60,90,180$ and 360 days, because curing in humid conditions, such as immersion into water, or the moist cure, which is applicable to cement mortar and ordinary concrete, is detrimental to latex-modified concrete and mortar.

Ohama (1995) stated that the optimal properties of modified systems can be achieved by a combination of wet and dry processing. In their work, Wang (2005), Ramli and Tabassi (2012a; $2012 \mathrm{~b}$ ) showed that a 6-day combined processing is more beneficial than wet processing. Moreover, Folic and Radonjanin (1998) indicated that the 6-day combined processing is more 
beneficial than the 2-day combined processing, with a wet processing throughout the entire period.

Humid period is used to hydrate cement and to avoid cracking due to plastic shrinkage (ACI Committee 548, 2003), while the dry period is used to evaporate the excess water to allow for the development of the polymer film (Ohama, 1995).

Reference mortars were immersed into water at $(20 \pm 3)^{\circ} \mathrm{C}$ until the day of the test, whereas the samples used to determine adherence on two different surfaces, i.e. brick and concrete substrate, were kept in the laboratory environment at $(20 \pm 3)^{\circ} \mathrm{C}$ with a $\mathrm{RH}=55 \pm 10 \%$, up to the day of the test. This was done to simulate the application in a real environment.

Table 5. Fresh and mechanical performance of mortars prepared with $\mathrm{W} / \mathrm{C}=0.5$ and 0.55

\begin{tabular}{|l|c|c|}
\hline Type Test & $\mathrm{W} / \mathrm{C}=0.5$ & $\mathrm{~W} / \mathrm{C}=0.55$ \\
\hline \hline Compressive strength (MPa). & 50.1 & 45.8 \\
\hline Flexural tensile strength (MPa) & 11.47 & 11.39 \\
\hline Fluidity (mm). & 125 & 165 \\
\hline
\end{tabular}

Table 6. Details of mixing proportions modified mortars

\begin{tabular}{|c|c|c|c|c|c|}
\hline Designation mixtures & Sand $(g)$ & $\begin{array}{c}\text { Cement } \\
(\mathrm{g})\end{array}$ & $P(g)$ & $\mathrm{W} / \mathrm{C}$ & $\begin{array}{c}\text { fluidity } \\
\text { (mm) }\end{array}$ \\
\hline M. Ref & 1350 & 450 & 0 & 0.5 & 125 \\
\hline \multicolumn{6}{|c|}{ Styrene Butadiene Rubber (SBR) } \\
\hline M. 2,5 \% SBR & \multirow{5}{*}{1350} & 438.75 & 25 & 0.498 & 125 \\
\hline M. $5 \%$ SBR & & 427.5 & 50 & 0.48 & 130 \\
\hline M. $10 \%$ SBR & & 405 & 100 & 0.425 & 145 \\
\hline M. $15 \%$ SBR & & 382 & 150 & 0.35 & 160 \\
\hline M. $20 \%$ SBR & & 360 & 200 & 0.25 & 165 \\
\hline \multicolumn{6}{|c|}{ Styrene Acrylic (SA) } \\
\hline M. 2,5 \% SA & \multirow{5}{*}{1350} & 438.75 & 22.5 & 0.498 & 125 \\
\hline M. $5 \%$ SA & & 427.5 & 45 & 0.48 & 125 \\
\hline M. $10 \%$ SA & & 405 & 90 & 0.425 & 125 \\
\hline M. $15 \%$ SA & & 382 & 135 & 0.35 & 125 \\
\hline M. $20 \% \mathrm{SA}$ & & 360 & 180 & 0.25 & 125 \\
\hline
\end{tabular}

\subsubsection{Test procedure}

The evaluation of the compressive strength and bending tensile strength was performed at 7,14 , 28, 60, 90, 180 and 360 days, according to standard EN 196-1 (2005), on specimens of dimensions $\left(40 \times 40 \times 160 \mathrm{~mm}^{3}\right)$. It is known from literature that these properties are the most important, if sustainability indicators are excluded.

The measurement of water absorption was done according to the method suggested by Ramli (2013). The test is usually measured on dried samples then partially immersed in water and the increase in mass as a percentage of the dry mass is measured. For the representativeness of the samples, a set of three cylindrical samples of size $70 \times 70 \mathrm{~mm}$ are placed in an oven for $72 \mathrm{~h}$ at a temperature of $105^{\circ} \mathrm{C}$. After drying to constant mass, the samples are removed and left in a sealed container for a period of $24 \pm 0.5 \mathrm{~h}$. Each sample was then weighed and immediately 
immersed in water for a period of $30 \pm 0.5 \mathrm{~min}$ (see Fig. 4.). The sample is then taken out of the water, the surface wiped and weighed again. Water absorption was calculated from the mass increase of the sample and expressed as a percentage of dry specimens multiplied by a correction factor as follows:

Correction factor $=\frac{\operatorname{Volume}\left(\mathrm{mm}^{3}\right)}{\operatorname{Area}\left(\mathrm{mm}^{2}\right) \times 12,5}$

As for adherence, several researchers have stated that the fundamental purpose of using polymers in the cementitious mixture is to improve the adherence and the durability of adhesion, because the quality of repair and protection of structures depends mainly on the adherence of mortars to the substrate to be repaired or protected (Courard, 1998). Previous works in this area have shown that the adhesion measurement tests are usually tests of rupture between two materials. They can be achieved either by pulling (traction) or flexural tensile and/or by direct or indirect shear (Ngassam, 2013; Momayez, 2005; Courard and Bissonnette, 2004).

In this work, the adhesion measurement was carried out using the method shown in Fig. 5. According to the literature, this test is easy to perform and can produce good results (Ngassam, 2013; Momayez, 2005).

The peel test by direct pulling, often called "pull-off", was performed on mortars used on hollow clay bricks and concrete substrate. The same formulations of mortars, previously defined, were applied on one of the larger faces of the brick $300 \times 200 \mathrm{~mm} 2$ and concrete $300 \times 300 \mathrm{~mm} 2$ (see fig. 6). These faces was wetted before applying mortar, to avoid the absorption of water of mortars in the fresh state, and maintaining a saturation level of the substrate higher than $50 \%$ and lower than 90\% for a good adherence (Mirza, 2014; Courard, 2011).

The thickness of the applied layer was $20 \mathrm{~mm}$. Such a choice was made because generally the thickness of repair or protection mortars exceeds $10 \mathrm{~mm}$, depending on the degree of damage. These mortars were tested after 28 days of curing. The samples were prepared by drilling three circular holes of diameter $50 \mathrm{~mm}$ on the mortars applied to the bricks and concrete, 24 hours before the test. Then, cylindrical metal disks of the same diameter $(50 \mathrm{~mm})$ were stuck on the removed parts with an epoxy adhesive. After 24 hours, a male ball, fixed on the metallic disks, was received in the ball socket which is located at the base of the central axis of the adhesion tester. The peel tests consist of applying a traction force on the male ball, perpendicularly to the surface of the disk, until rupture (see Fig. 6.).

The value of adhesion (in MPa) of the coating to the brick and concrete is obtained by dividing the maximum force of the fracture (in N) by the surface of the bonded surface $\left(\mathrm{mm}^{2}\right)$. This value was recorded, and the fracture interface was analyzed in each case.

Adherence $(M P a)=\frac{P(N)}{A\left(m m^{2}\right)}$

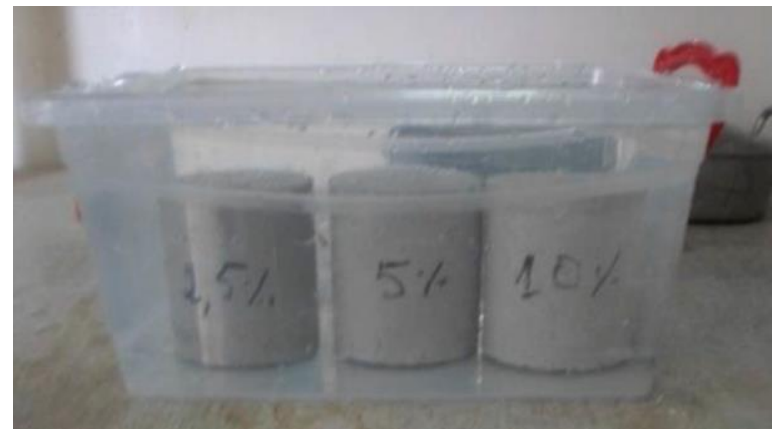

Fig 4. Water absorption test. 


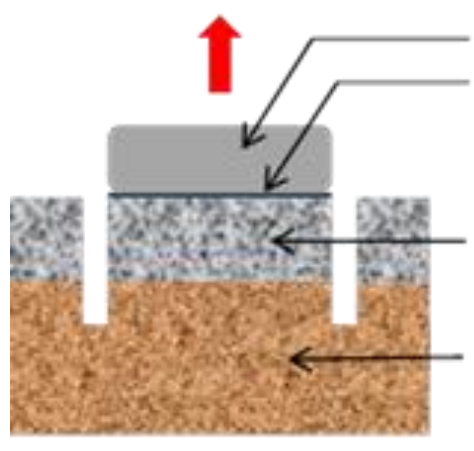

Cylindrical metal disks

Epoxy adhesive

Layer of applied mortar

Substrate

\section{Several geometries are used}

Fig 5. Schematic of the method used for measuring adhesion "Pull off".

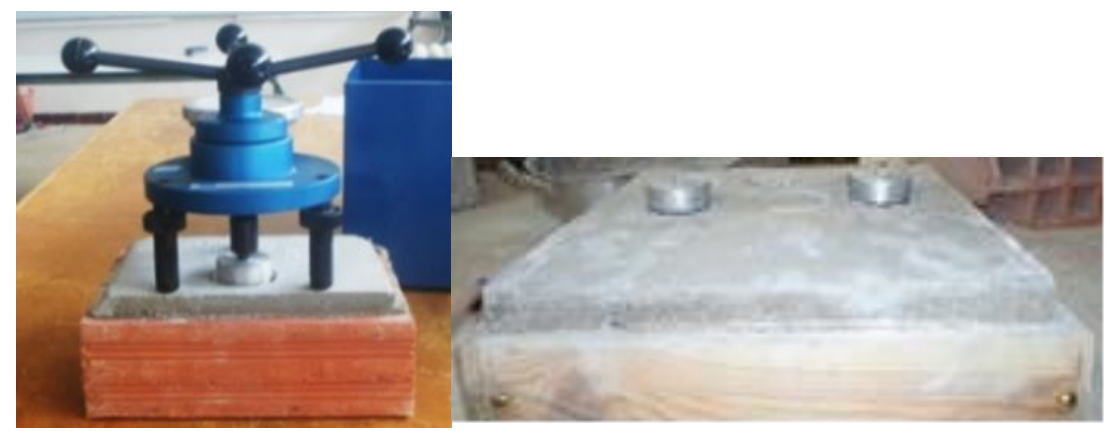

Fig 6. Adhesion test on clay brick and concrete substrates.

\section{Results and discussion}

\subsection{Flow}

According to the results shown in Fig 7 and 8, it is easy to see that both types of latex, i.e. SA and SBR, are water reducers. Similar observations on the effect of latex on a fresh cementitious matrix were made by Barluenga and Hernandez-Olivares (2004), Ohama (1995), Wang and Wang (2010) and Ngassam (2013).

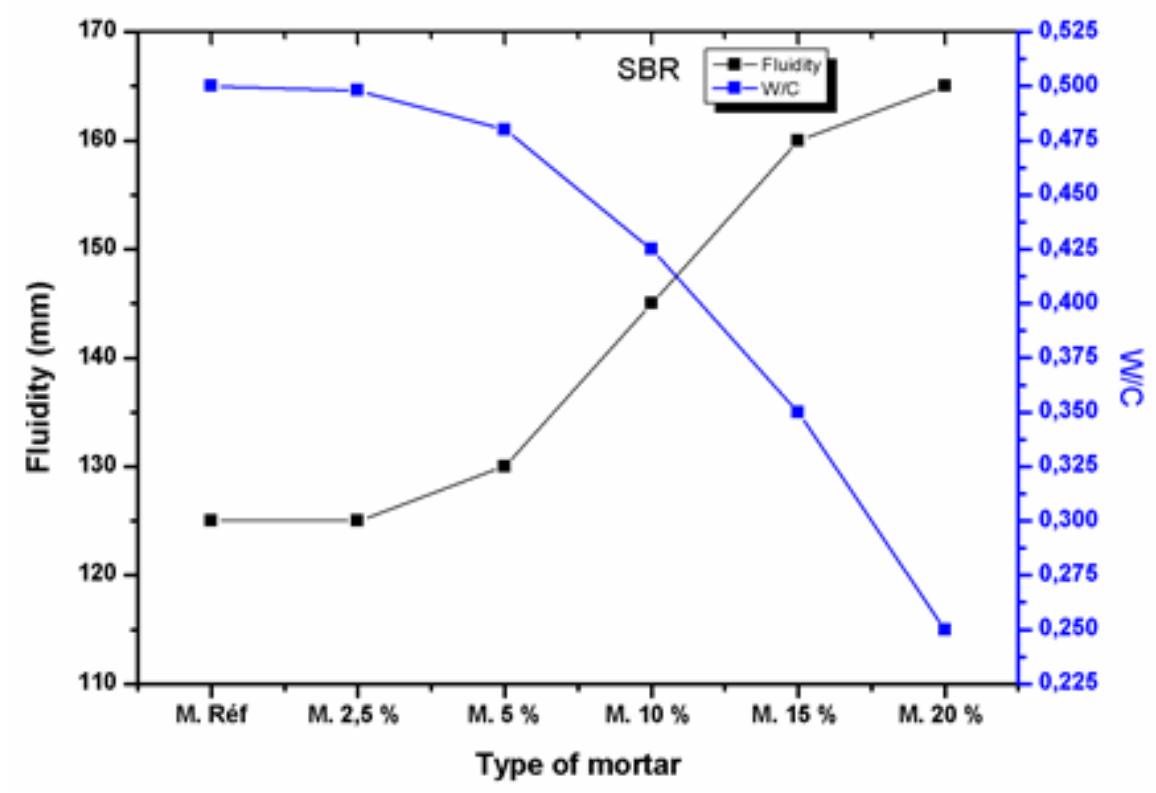


Fig 7. Fluidity and $\mathrm{W} / \mathrm{C}$ as a function of polymer SBR content mortars.

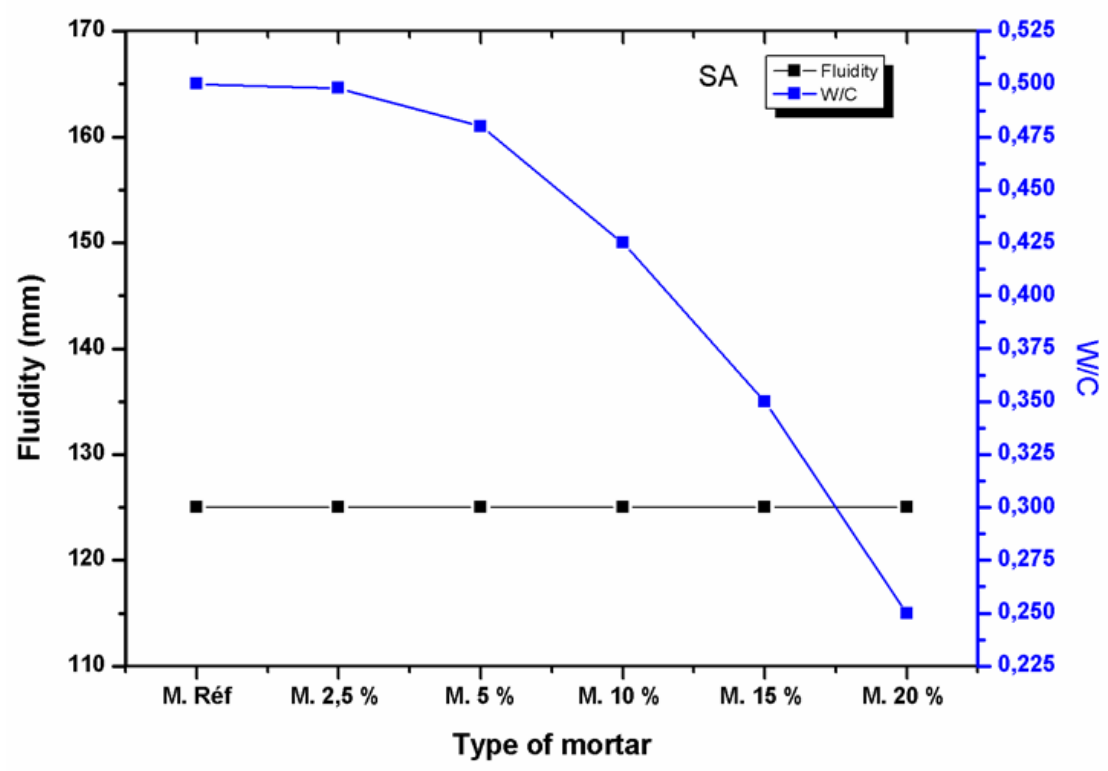

Fig 8. . Fluidity and $\mathrm{W} / \mathrm{C}$ as a function of polymer SA content mortars.

Indeed, when the substitution rates went from 0 to $20 \%$, the fluidity of fresh mixture increased significantly, from $125 \mathrm{~mm}$ to $165 \mathrm{~mm}$ for SBR, but remained constant at $125 \mathrm{~mm}$ for SA, while the $(\mathrm{W} / \mathrm{C})$ ratio dropped from 0.5 to 0.25 .

This may be interpreted as an improved coherence, due to the ball-bearing action of the polymer particles, their dispersion, the entrapped air, and the plasticizing effect of latex.

Therefore, the obtained results show that the two types of latex are water reducers, but SBR is a higher range water reducer than SA latex. This may be due to the large amount of water existing in SBR $(\approx 55 \%)$.

\subsection{Compressive strength}

The results of the compressive strength of control mortars as well as those modified by SBR and SA as a function of polymer content and age are shown on the semi-logarithmic chart in figures 9 and 10, respectively. These results are the average of six tests on fragments recovered from the flexural tensile strength test.

A preliminary analysis of the results allows making the following observations. The evolution curves of the compressive strength versus time (7 to 360 days) show the same trend. Overall, the strength of all mortars increases steadily with the conservation period (from7 to 60 days) of specimens. Beyond that age, the strength of all mortars remains constant, taking into account the experimental uncertainties. This may be attributed to the time required for cement hydration and its curing. Moreover, when examining more closely the values obtained at specific ages, it is found that reference mortars develop greater compressive strengths, at all ages ( 7 to 360 days). It is obvious that the compressive strength of mortars decreases (loss) while the cement substitution rate increases, for all examined maturities. This loss is $21,33,32,34$ and $35 \%$, when the strength of reference mortars is compared to that of mortars modified by SBR at the age of 360 days. It is $23,28,32,33$ and $34 \%$ when the strength of reference mortars is compared to that of mortars modified by SA at the same age. Note that beyond $10 \%$ of polymer additions, the values of strength are generally similar. 


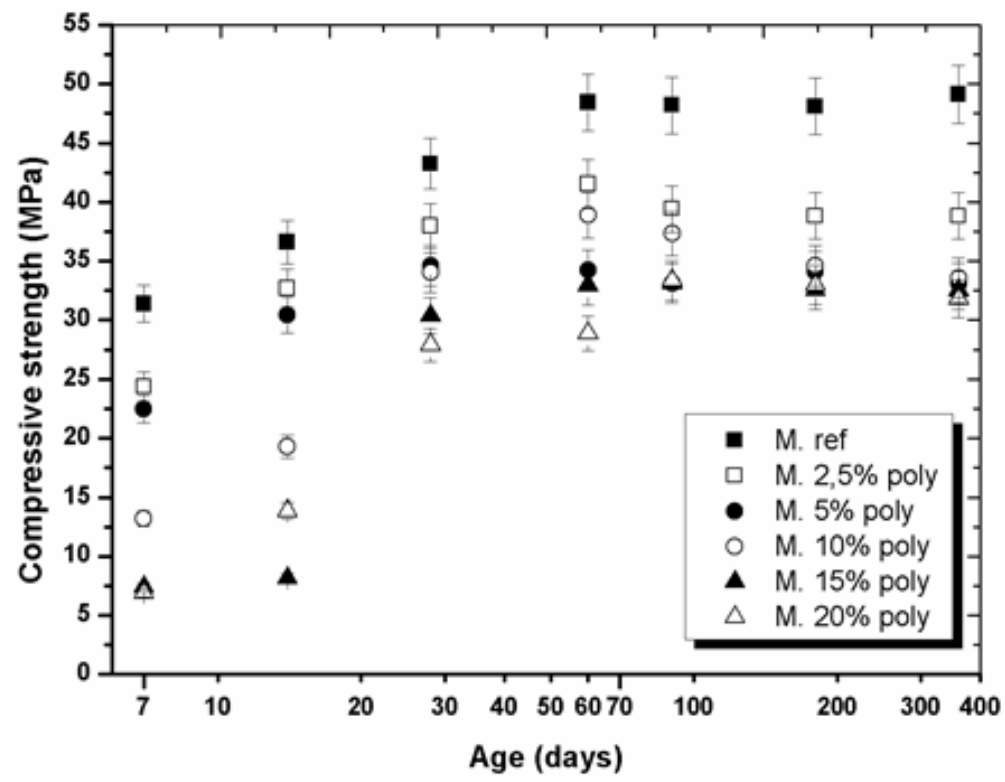

Fig 9. . Influence of age on the compressive strength as a function of polymer SBR content mortars.

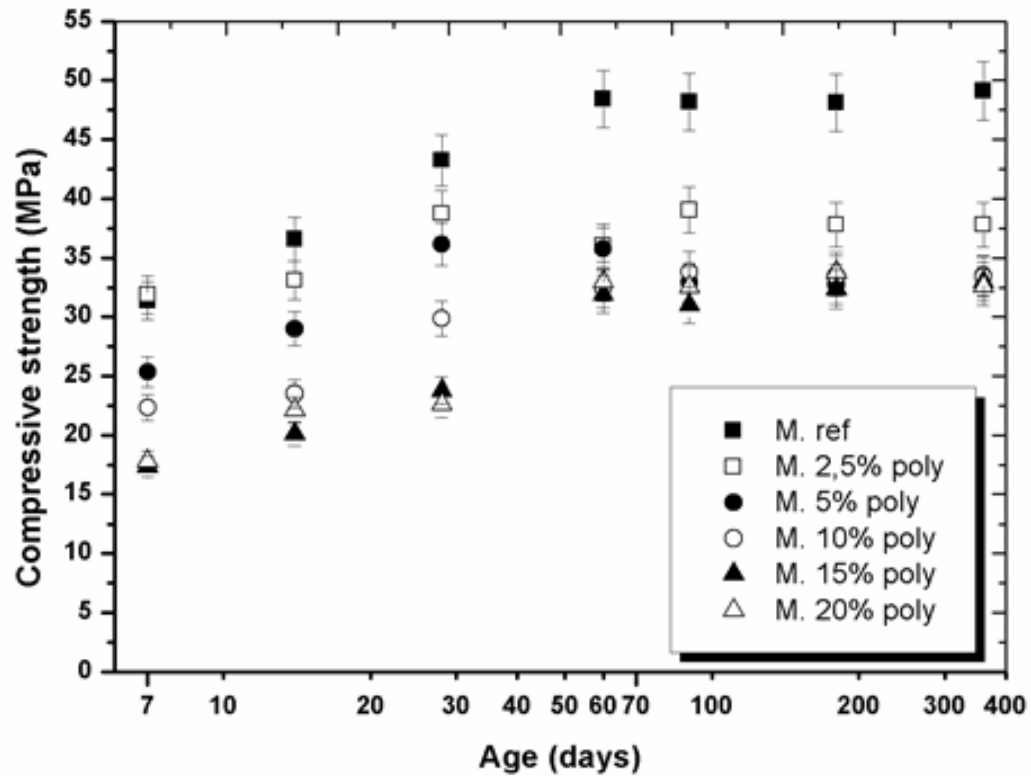

Fig 10. . Influence of age on the compressive strength as a function of polymer SA content mortars.

Several research studies have shown that the presence of polymers has a low impact on the compressive strength, and it may even have a negative impact (ACI Committee 548, 2003; Ngassam, 2013). Most of these authors justified these observations by the fact that a polymer has a larger capacity of water retention, a high closed porosity due to air entrainment by the polymer (Wang, 2005; Wang and Wang, 2010; Ngassam, 2013) and also to the delay in hydration of cement, caused by the presence of surfactants in the mixture (Sikora, 2015). However, other researchers (Barluenga and Hernandez-Olivares, 2004; Ramli and Tabassi, 2012b) justified these same observations by the low mechanical capacity of the latex and also by the change observed in the microstructure of the mixture. In the co-matrix network of modified mortars, there are two types of bonds, i.e. cement-cement and cement-polymer. The cement-polymer bonds are weaker than the cement-cement bonds. When the polymer content increases, the polymer film covers the hydrated cement and aggregates, thus forming several polymer-cement 
bonds. This results in a decrease in the compressive strength of the modified samples.

\subsection{Flexural tensile strength}

The flexural tensile strength of reference and modified mortars as a function of age and polymer content is represented on the semi-logarithmic chart, in figures 11 and 12, respectively. These results represent the average of three tests on prismatic specimens of dimensions $(40 \times 40 \times 160$ $\left.\mathrm{mm}^{3}\right)$.

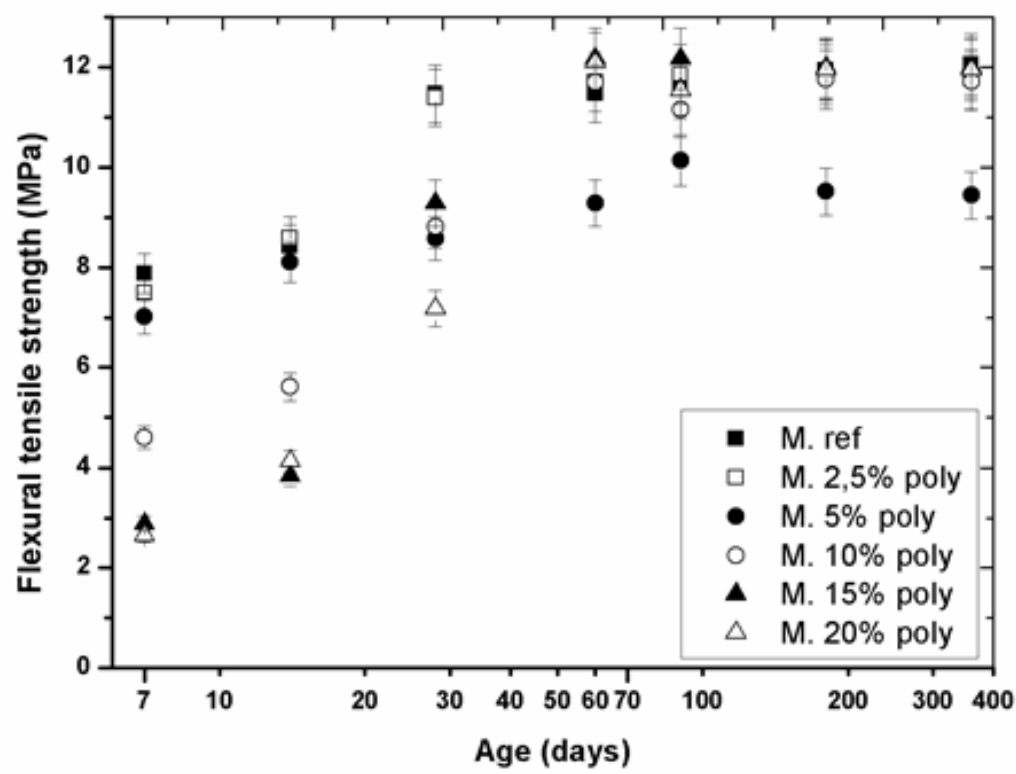

Fig 11. . Influence of age on the flexural tensile strength as a function of polymer SBR content mortars.

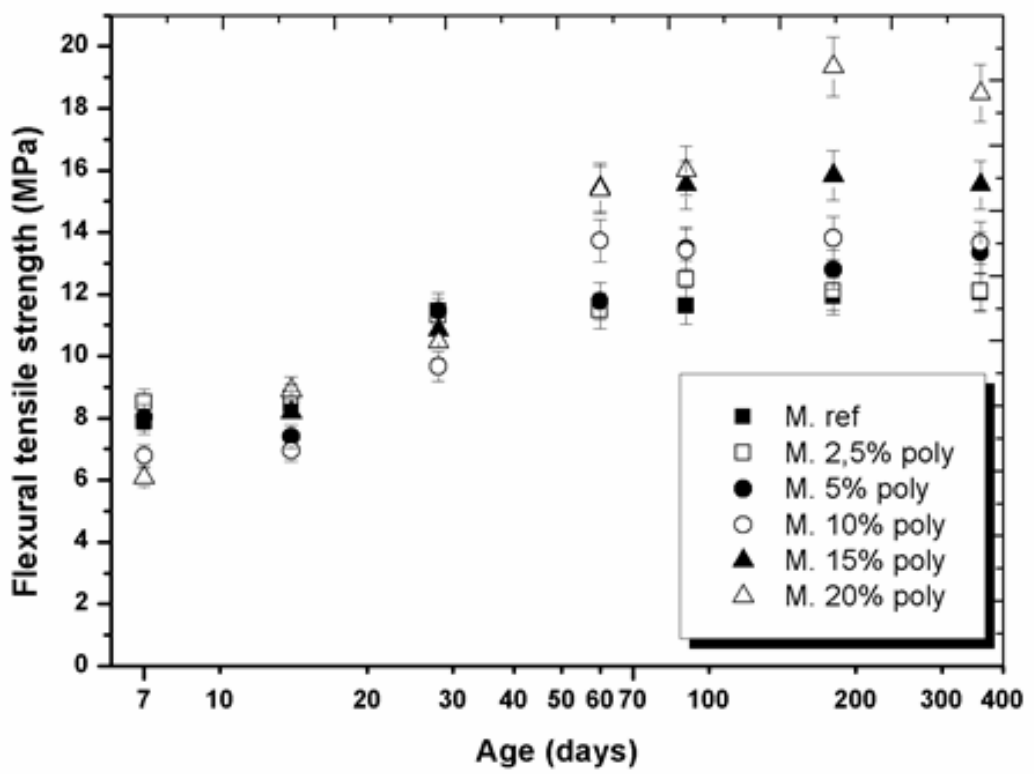

Fig 12. . Influence of age on the flexural tensile strength as a function of polymer SA content mortars.

Based on these experimental results, it can be stated that the flexural tensile strength of all polymer-modified and reference mortars increases steadily. Similarly, the compressive strength also rises with the conservation period of specimens, from 7 to 60 days. Beyond that age, the strength of mortars follows a constant trend, provided that the experimental uncertainties are taken into consideration. This is due, as previously said for the compressive strength, to the 
hydration of cement, its hardening and also to the formation of the polymer film over time. These results corroborate those found in the literature (Barluenga and Hernandez-Olivares, 2004; Wang, 2005; Wang and Wang, 2010).

Figures 11 and 12 also show that the flexural tensile strength of mortars decreases when the substitution rate of polymer increases, for all maturities (7 to 28 days). The reduction in strength may be attributed to the amount of substituted cement, delayed cement hydration under dry conditions, the fixing of polymer particles on cement particles, and also to the comatrix and the undeveloped polymer film. However, the loss in strength is recovered at 60 days. This strength increases by $5 \%$ and $34 \%$, respectively, when mortars modified with $20 \%$ of SBR and $20 \%$ SA, are compared to control mortars. This can be explained by the improved cohesion between the aggregates and cement paste. This cohesion is enhanced by the formation of the polymeric film and the co-matrix which is a network structure in which the hydrated cement phase and the polymer phase interpenetrate.

Comparing the two figures 11 and 12 enables to note that the flexural tensile strength of mortars modified with SA shows better improvement than that of mortars modified with SBR. This is due to the nature and functioning of the polymer as well as to the amount of water that exists in mortar; the quantity of water in mortars modified by SBR is larger than that encountered in those modified by SA, for identical polymer contents.

Our results confirm the conclusions of Gemert (2005) and Ngassam (2013). The beneficial effect of polymers is generally more noticeable in the flexural tensile strength than in the compressive strength because polymers enhance the strength of the binder-aggregate interface, which is particularly needed during the flexural tensile tests.

\subsection{Adhesion to bricks and cementitious substrates}

The results of the adhesion of control and modified mortars to bricks and concrete substrates as a function of the substitution rates are illustrated in fig 13 and 14. These results are the average of the values obtained from three tests on mortars applied to clay bricks and cementitious substrates.

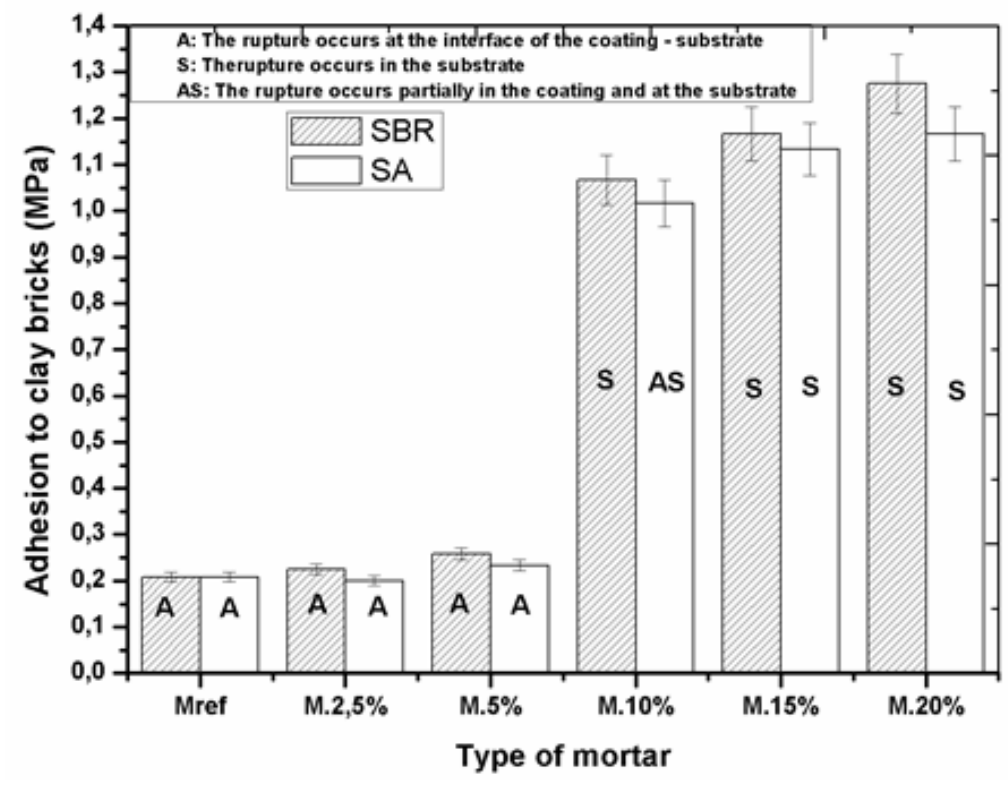

Fig 13. . Adhesion of mortars to clay bricks. 


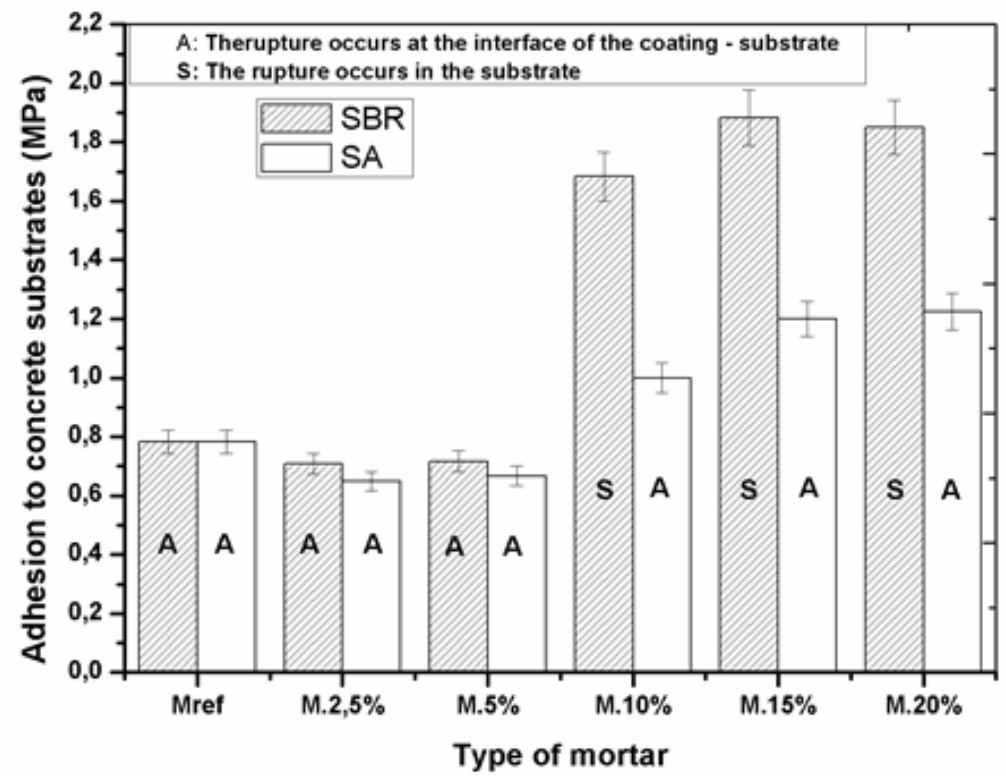

Fig 14. . Adhesion of mortars to concrete substrates

The adhesion to bricks was reported to be significantly influenced by the cement substitution rate. This influence is more noticeable beyond 5\% cement replacement by the two types of latex. Mortars modified by styrene butadiene (SBR) and styrene acrylic (SA) showed an adhesion increase to bricks of $84 \%$ and $82 \%$, respectively, for a $20 \%$ replacement rate for both latex compared to ordinary control mortars. Moreover, the adhesion increase to concrete substrates as those of bricks; however, the influence on this support is greater. The incorporation of $20 \%$ of styrene-butadiene (SBR) and acrylic styrene (SA) respectively resulted in a respective increase of $58 \%$ and $36 \%$, compared with reference mortars.

The improvement in adhesion is mainly attributed to the formation of a polymer film and hydrated cement compounds at the interface between the modified mortar and substrate (Mansur, 2009; Ngassam, 2013; Pierre, 2008). Latex films interweave cement hydrates, forming the monolithic polymer- cement co-matrix structure at the interface (modified mortar substrate), and come bridging the pores and cracks in this interface (Mansur, 2009)

Furthermore, the substrates used in this study are known to be very porous materials; according to Mansur (2009), the adhesion of modified mortars to substrates, which have a high water absorption ( $>6$ wt.\%) (very porous), exhibits a mechanical anchoring and a general improvement in mortars properties in addition to the formation of a continuous polymer film at the interface. It can be said that the latex and cement hydrates can seep into the porous network of substrates (clay bricks and concrete substrates), and thus adhere strongly to these substrates. Our results are in good agreement with the results found by Mansur (2009). The model developed by these authors, which explain the mechanisms of adhesion at the interfaces between the mortars and porous substrates, can summarize our results.

A closer examination of the results allows noting that better adhesion properties were obtained with SBR-modified mortars, especially for significant substitution rates, compared with mortars modified by SA. An explanation was suggested by Ngassam (2013) on the adhesion of mortars modified with the ethylene-vinyl acetate (EVA) and the styrene acrylic (SA). The best adhesion performance obtained for mortars modified with SBR is due to their rheological behavior. Indeed, these mortars have a higher fluidity than that encountered in mortars containing SA (see Table 6). 
Several researchers (Ngassam, 2013; Courard, 1998) defined fluidity in terms of the wettability of the material; they stated that the material should have good wettability and a good flow in order to increase the effective contact surface area between mortar and the substrate. This will certainly improve the adhesion strength of mortars to the different substrates.

Figs 15 and 16 show the failure mode of the samples, after the peel test.

In the case of bricks, it is noted that beyond $10 \%$ cement replacement by latex, the failure is purely cohesive within the substrate layer, unlike the case of low replacement levels where the failure is nearly at the interface. At the rate of $10 \%$ substitution by SA, the failure is cohesive both within the substrate and at the interface.

By cons, for concrete substrates, the failure is reported at the interface, for all the mortars modified by the SA, which means that the failure is not cohesive, whereas the SBR develops a cohesive failure in the substrates of mortars modified with latex levels greater than $10 \%$. This is probably due to the nature of the surface of the concrete substrates (harder than the surface of the bricks), and also to the high fluidity of the mortars modified by the SBR.

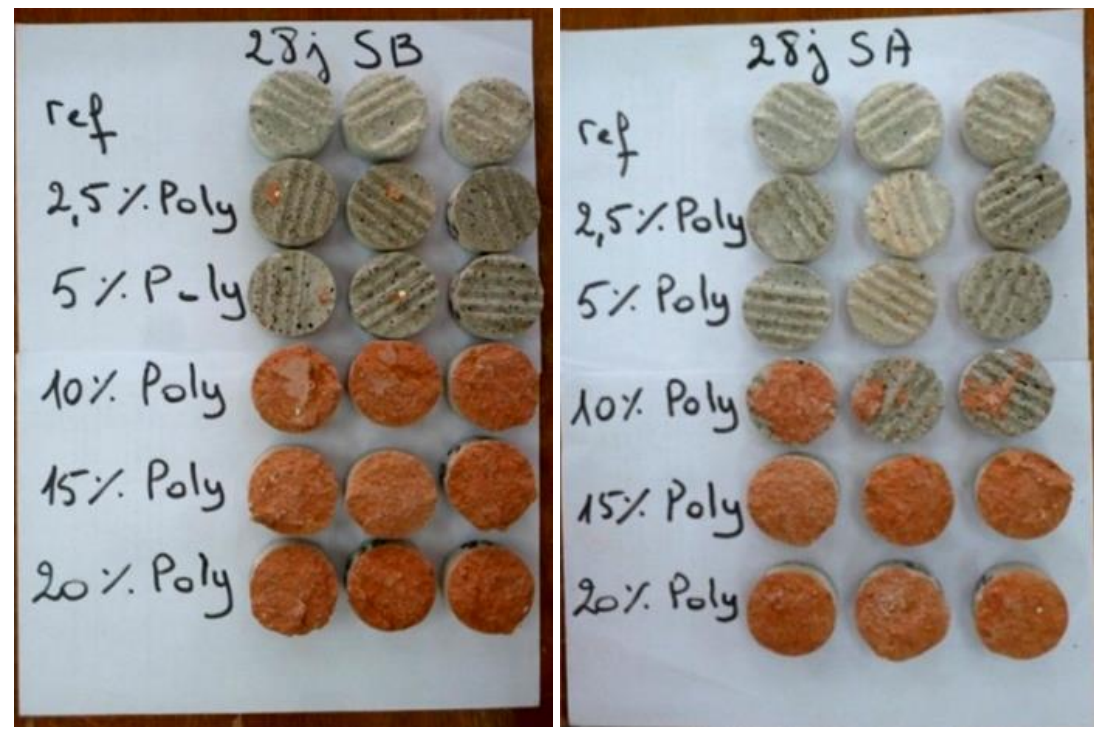

Fig 15. Failure mode of the samples clay bricks - mortars.

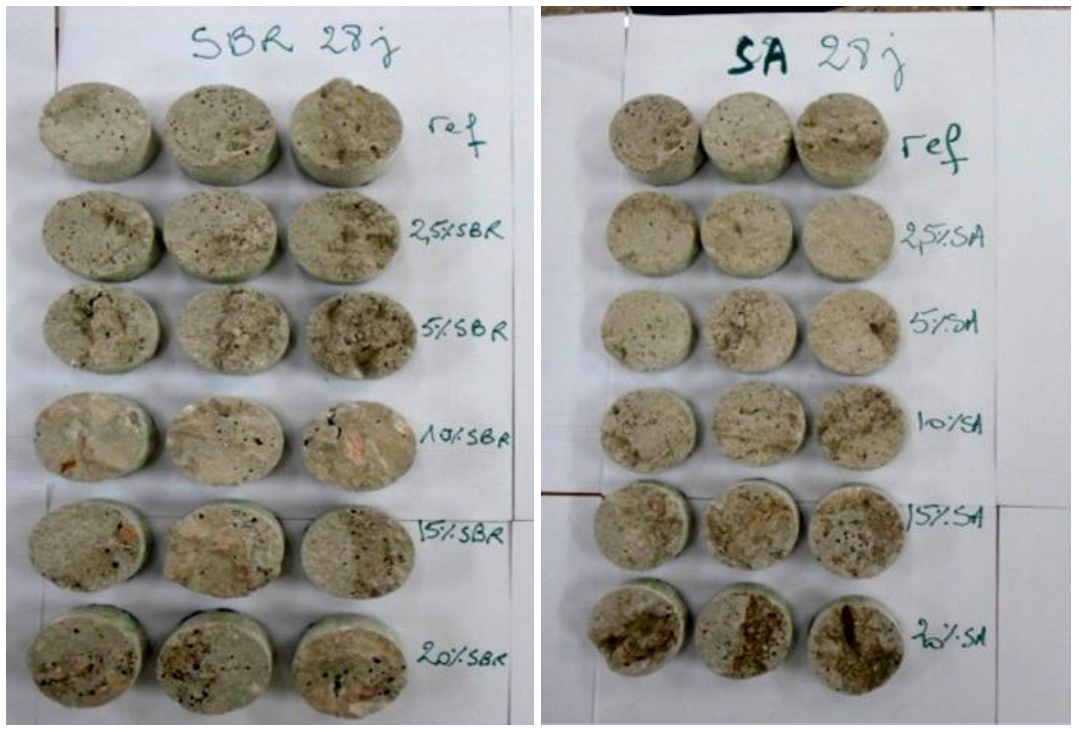

Fig 16. Failure mode of the samples concrete substrates - mortars. 


\subsection{Water absorption}

The polymeric film fills the pores and voids that generally occur in Portland cement mortars. This filling of the cracks increases with the increasing polymer content introduced into the cementitious matrix. As a result, a significant decrease in water absorption is reported as shown in Fig. 17.

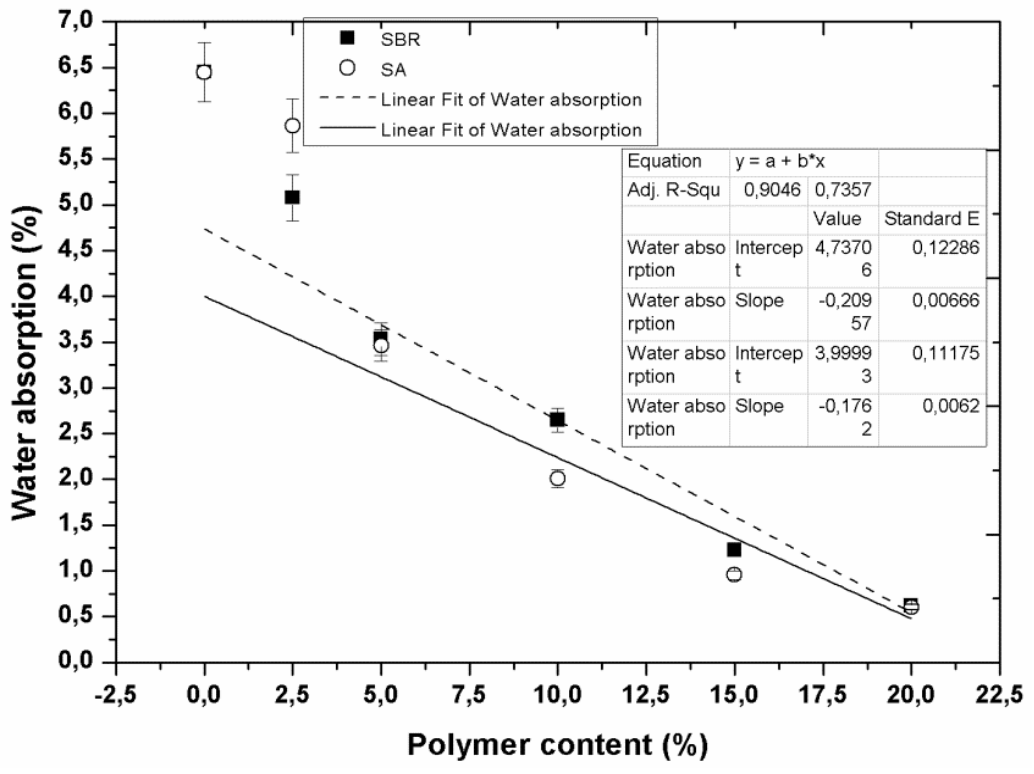

Fig 17. water absorption of modified mortars

There is a marked reduction in the percentage of water absorption with the increase in the substitution rate. Indeed, the increase of this latter from 0 to $20 \%$ resulted in a reduction near to $90.5 \%$ of the water absorption for the two polymers. At this stage it can be said that the water absorption of the mortars modified by the SBR and the SA is proportional to the substitution dosage and follows a linear trend with satisfactory correlation coefficients of 0.90 and 0.73 .

\section{Conclusions}

Based on the results and discussion presented in this paper, the following conclusions can be drawn:

- Increasing the substitution levels of cement by the latex (SBR and SA), in the cementitious mix, leads to a significant influence on the fluidity and a reduction in the quantity of mixing water. Therefore, the latex can be successfully used as water reducers.

- The flexural tensile strength increases with the increase in latex content in the mix beyond 60 days. However, the compressive strength increases with the increase in cement content and with age.

- A significant decrease in water absorption is reported in the mortars modified in comparison with the reference mortars.

- SBR- and SA-modified mortars also cause an increase in the bond strength of mortars to clay bricks and to concrete substrates as well. Beyond $10 \%$ cement replacement, failure in modified mortars is purely cohesive within clay substrates, unlike the case of low substitution levels where the failure occurs at the interface. However, for concrete substrates, the failure is reported at the interface, for all the mortars modified by the SA, whereas the SBR develops a cohesive failure in the substrates of mortars modified with latex levels greater than $10 \%$ of substitution. 


\section{References}

ACI Committee 548. (2003). Polymer-modified concrete (pp. 40). Farmington Hills (MI): American Concrete Institute.

Al-Zahrani, M. M., Maslehuddin, M., Al-Dulaijan, S. U., \& Ibrahim, M. (2003). Mechanical properties and durability characteristics of polymer- and cement-based repair materials. Cement \& Concrete Composites, 25, 527-537.

Amaral, M. d. (2004). Assessing the environmental cost of recent progresses in emulsion polymerization. Reactive \& Functional Polymers, 58, 197-202.

ASTM C373-88. (2006). Standard test method for water absorption, bulk density, apparent porosity, and apparent specific gravity of fired whiteware products (pp. 2). West Conshohocken (PA): ASTM International.

ASTM C1437-07. (2007). Standard test method for flow of hydraulic cement mortar (pp. 2): West Conshohocken (PA): ASTM International.

Balayssac, J. P., Nicot, P., Ruot, B., Devès, O., \& Détriché, C. H. (2011). Influence of admixtures on the cracking sensitivity of mortar layers applied to a mineral substrate. Construction and Building Materials, 25, 2828-2836.

Barluenga, G., and Hernandez-Olivares, F. (2004). SBR latex modified mortar rheology and mechanical behaviour. Cement and Concrete Research, 34, 527-535.

Benali, Y., and Ghomari, F. (2017). Latex influence on the mechanical behavior and durability of cementitious materials. Journal of Adhesion Science and Technology, 31(3), 219-241.

Boukli Hacene, S. M. E. A. (2009). Contribution a l'étude de la résistance caractéristique des bétons de la région de Tlemcen [ Contribution to the study of the characteristic strength of the concrete in the region of Tlemcen]. [PhD thesis], University of Abou Bekr Belkaid, Algeria.

BS EN196-1. (2005). Methods of testing cement - Part 1: determination of strength (pp. 28). London: Br. Stand Institution.

Courard, L. (1998). Contribution à l'analyse des paramètres influençant la création de l'interface entre un béton et un système de réparation [Contribution to the analysis of the parameters influencing the creation of the interface between a concrete and a repair system]. [PhD thesis], University of Liège, Belgium.

Courard, L., and Bissonnette, B. (2004). Essai dérivé de l'essai d'adhérence pour la caractérisation de la cohésion superficielle des supports en béton dans les travaux de réparation : analyse des paramètres d'essai [Adaptation of the pull-off test for the evaluation of the superficial cohesion of concrete substrates in repair works: analysis of the test parameters]. Materials and Structures, 37, 342-350.

Courard, L., Lenaers, J.-F., Michel, F., \& Garbacz, A. (2011). Saturation level of the superficial zone of concrete and adhesion of repair systems. Construction and Building Materials, 25(5), 2488-2494.

Diab, A. M., Elyamany, H. E., \& Ali, A. H. (2013). Experimental investigation of the effect of latex solid/water ratio on latex modified co-matrix mechanical properties. Alexandria Engineering Journal, 52, 8398.

Diab, A. M., Elyamany, H. E., \& Ali, A. H. (2014). The participation ratios of cement matrix and latex network in latex cement co-matrix strength. Alexandria Engineering Journal, 53, 309-317.

Erdmenger, T., Guerrero-Sanchez, C., Vitz, J., Hoogenbooma, R., \& Schubert, U. S. (2010). Recent developments in the utilization of green solvents in polymer chemistry. Chemical Society Reviews, $39(8), 3317-3333$.

Eren, F., Gödek, E., Keskinates, M., Tosun-Felekoglu, K., \& Felekoglu, B. (2017). Effects of latex modification on fresh state consistency, short term strength and long term transport properties of cement mortars. Construction and Building Materials, 133, 226-233. 
Folic, R. J., and Radonjanin, V. S. (1998). Experimental Research on Polymer-Modified Concrete. ACI Materials Journal, 95(4), 463-468.

Gemert, D. V., Czarnecki, L., Maultzsch, M., Schorn, H., Beeldens, A., Łukowski, P., \& Knapen, E. (2005). Cement concrete and concrete-polymer composites: Two merging worlds. A report from 11th ICPIC Congress in Berlin, 2004. Cement \& Concrete Composites, 25, 926-933.

Kim, J.-H., \& Robertson, R. E. (1997). Prevention of air void formation in polymer-modified cement mortar by pre-wetting. Cement and Concrete Research, 27(2), 171-176.

Mansur, A. A. P., Nascimento, O. L. d., \& Mansur, H. S. (2009). Physico-chemical characterization of EVAmodified mortar and porcelain tiles interfaces. Cement and Concrete Research, 39, 1199-1208.

Mirza, J., Durand, B., Bhutta, A. R., \& Tahir, M. M. (2014). Preferred test methods to select suitable surface repair materials in severe climates. Construction and Building Materials, 50, 692-698.

Momayez, A., Ehsani, M. R., Ramezanianpour, A. A., \& Rajaie, H. (2005). Comparison of methods for evaluating bond strength between concrete substrate and repair materials. Cement and Concrete Research, 35, 748-757.

Ngassam, I. L. T. (2013). Durabilité des réparations des ouvrages d'art en Béton [Durability of repairing concrete structures]. [Phd thesis]. University of Paris-Est, France.

Ohama, Y. (1995). Handbook of polymer-modified concrete and mortars. properties and process technology: Park Ridge (NJ): Noyes Publications.

Parghi, A., \& Alam, M. S. (2016). Effects of curing regimes on the mechanical properties and durability of polymer-modified mortars - an experimental investigation. Journal of Sustainable Cement-Based Materials, 5(5), 324-347.

Pierre, N. (2008). Interactions mortier-support : éléments déterminants des performances et de [Mortarsupport interactions: determinants element of performance and adhesion of mortar]. [Phd thesis]. University of Toulouse, France.

Ramli, M., and Tabassi, A. A. (2012a). Effects of Different Curing Regimes on Engineering Properties of Polymer-Modified Mortar. Journal of Materials in Civil Engineering, 24, 468-478.

Ramli, M., and Tabassi, A. A. (2012b). Mechanical behaviour of polymer-modified ferrocement under different exposure conditions: An experimental study. Composites: Part B, 43, 447-456.

Ramli, M., Tabassi, A. A., \& Hoe, K. W. (2013). Porosity, pore structure and water absorption of polymermodified mortars: An experimental study under different curing conditions. Composites: Part B, $55,221-233$.

Said, A. M., Quiroz, O. I., Hatchett, D. W., \& Elgawady, M. (2016). Latex-modified concrete overlays using waste paint. Construction and Building Materials, 123, 191-197.

Sikora, P., Łukowski, P., Cendrowski, K., Horszczaruk, E., \& Mijowskab, E. (2015). The effect of nanosilica on the mechanical properties of polymercement composites (PCC). Procedia Engineering, 108, $139-145$.

Thickett, S. C., \& Gilbert, R. G. (2007). Emulsion polymerization: State of the art in kinetics and mechanisms. Polymer, 48, 6965-6991.

Wang, R., Wang, P.-M., \& Li, X.-G. (2005). Physical and mechanical properties of styrene-butadiene rubber emulsion modified cement mortars. Cement and Concrete Research, 35, 900- 906.

Wang, R., \& Wang, P. (2010). Function of styrene-acrylic ester copolymer latex in cement mortar. Materials and Structures, 43, 443-451.

Xu, F., Peng, C., Zhu, J., \& Chen, J. (2016). Design and evaluation of polyester fiber and SBR latex compoundmodified perlite mortar with rubber powder. Construction and Building Materials, 127, 751-761. 